\title{
SCIENTIFIC REP RTS \\ Development of an oxidative stress in vitro assay in zebrafish (Danio rerio) cell lines
}

Received: 6 June 2018

Accepted: 6 August 2018

Published online: 17 August 2018

\author{
Sebastian Lungu-Mitea, Agneta Oskarsson \& Johan Lundqvist (iD
}

The nuclear factor erythroid 2-related factor 2 (Nrf2) is a key regulator of cellular defense against oxidative stress and correlated with classical toxicological endpoints. In vitro methods using fish cell lines for the assessment of aquatic toxicity are needed for mechanistic studies and as an alternative to in vivo. We describe an in vitro assay to study oxidative stress using zebrafish cell lines. Transfection efficiency of twelve commercially available transfection reagents were tested in the zebrafish cell lines ZFL, ZF4, and Pac2. The most efficient reagent for each cell line was selected for further experiments. Cells were transiently transfected with an Nrf2-responsive luciferase plasmid. The assay was tested using the oxidative stress inducing chemicals tertbutylhydroquinone, hydrogen peroxide, and sulforaphane. Of the transfected cell lines, ZF4 and ZFL showed higher sensitivity. The latter were used to study potential oxidative stress induced by pesticides (diazinon, deltamethrin, atrazine, metazachlor, terbutylazine, diuron). Besides known inducers, Nrf2 activity was also significantly induced by diazinon, deltametrin, diuron, and metazachlor. Activation of Nrf2 by metazachlor is a novel finding. The described assay could be a valuable tool for research in toxicology to study the stress response of both pure chemicals and environmental water samples.

Oxidative stress, with formation of reactive oxygen species (ROS), is a mechanism underlying a number of toxicity processes ${ }^{1}$. The nuclear factor erythroid 2-related factor 2 (Nrf2) is a keystone in the cellular defense against oxidants and the regulation of oxidative stress detoxification, metabolism, and induction of related phase-II enzymes (glutathione S-transferase (GST), NADPH-quinone oxireductase 1 (NQO1), heme oxygenase 1 (HO-1), g-glutamylcysteine synthetase (g-GCS), thioredoxin (TRX) $)^{2}$. The antioxidant responsive element (ARE) sequence ("RTGACnnnGC") ${ }^{3,4}$ is located upstream in the regulatory region of the phase-II metabolizing enzymes genes, often coinciding with the xenobiotic response element (XRE) ${ }^{5}$. Nrf2 occurs ubiquitously under normal physiological conditions in the cytosol where it is bound to its negative regulator Kelch-like ECH-associated protein 1 (Keap1), which marks it for degradation ${ }^{6}$. Upon conditions of oxidative stress Nrf2 is released from Keap1 and avoids proteolysis. Nrf2 then translocates and accumulates within the nucleus where it heterodimerizes with small Maf proteins and initiates gene expression ${ }^{7}$ by binding to AREs. The Keap1-Nrf2-ARE signaling pathway is highly conserved within vertebrates ${ }^{8-10}$. In ToxCast ("toxicity forecaster", an online database by the US Environmental Protection Agency, USEPA, https://www.epa.gov/chemical-research/toxcast-dashboard) high-throughput data on toxicity, e.g. Nrf2 activity, of single chemicals are collected. Nrf2 activity has been shown to be correlated with classical toxicological endpoints in vivo and it has therefore been suggested that oxidative stress response and Nrf2 activity would be an ideal pathway to build in vitro toxicity assays on ${ }^{11}$.

In vivo assays are extensively used in assessment of aquatic toxicity of chemicals. The high number of animals used in environmental risk assessment has highlighted the need for novel approaches and development of in vitro assays. Development of fish cell culture-based in vitro assays has been proposed as a promising idea to reduce and replace the use of fish in aquatic toxicity testing, e.g. by the European Union Reference Laboratory for Alternatives to Animal Testing (EURL ECVAM) ${ }^{12-14}$. Development of such in vitro models would allow subsequent high throughput screening and application of omics technologies. Cell cultures and embryo tests have emerged as useful alternative approaches in environmental toxicology ${ }^{15}$.

Reporter gene assays in transfected mammalian cells have been shown to be a valuable tool for research in many fields of toxicology ${ }^{16-19}$. However, the use of fish cell lines for reporter gene assays has been very limited

Department of Biomedicine and Veterinary Public Health, Swedish University of Agricultural Sciences, Box 7028, SE-750 07, Uppsala, Sweden. Correspondence and requests for materials should be addressed to S.L.-M. (email: sebastian.lungu@slu.se) 
and this type of approach is still in its infancy within aquatic toxicology. A requirement for the development of reporter gene assays, is the availability of functioning transfection methods. Most transfection reagents were developed for mammalian cell lines and are based on lipid-fusion mechanisms. However, the latter might be less efficient in fish cells due to lower incubation temperatures ${ }^{20}$. Furthermore, the transfection efficiency for a specific transfection regent often varies greatly between cell lines ${ }^{21}$. Thus, in the present investigation cells of different developmental stages and tissue origin were tested.

In this study, we have established a reporter gene assay for detecting oxidative stress by measuring induction of free Nrf2 in zebrafish cell lines Pac2, ZF4, and ZFL. Initially, we tested the transfection efficiency of twelve commercially available transfection reagents for these three cell lines. The established reporter gene assays were tested with potential Nrf2 inducers and six pesticides which are suspected to cause oxidative stress ${ }^{22}$. The established in vitro bioassay might be a useful tool in screening for potential inducers of oxidative stress, both regarding toxicity of pure compounds and for analysis of environmental samples, e.g. for ecotoxicology and environmental monitoring.

\section{Materials and Methods}

Cell culture. Zebrafish fibroblast cell line Pac 2. Zebrafish fibroblast cell line Pac $2^{23,24}$ (CVCL_5853) was cultured in Leibovitz's L-15 medium containing phenol red (Sigma-Aldrich, Steinheim, Germany), supplemented with 15\% fetal bovine serum (Gibco, Paisley, UK), 1\% penicillin-streptomycin $100 \mathrm{U} / \mathrm{mL}$ (Gibco, Paisley, UK), $1 \%$ gentamicin $50 \mathrm{mg} / \mathrm{mL}$ (Lonza, Basel, Swiss). The cells were cultured in a humidified environment at $28^{\circ} \mathrm{C}$ and atmospheric $\mathrm{CO}_{2}$. The cells were passaged weekly in a 1 to 3 ratio, using PBS (Medicago, Uppsala, Sweden) for washing and $0.25 \%$ Trypsin-EDTA (Sigma-Aldrich, Steinheim, Germany) for detachment.

Zebrafish fibroblast cell line ZF4. Embryonic zebrafish fibroblast cell line ZF4 ${ }^{25}$ (CVCL_3275) was cultured in Dulbecco's modified Eagle's medium/Ham's Nutrient Mixture F-12 (DMEM:F12) containing phenol red (Gibco, Paisley, UK), supplemented with $10 \%$ fetal bovine serum (Gibco, Paisley, UK), 1\% penicillin-streptomycin $100 \mathrm{U} / \mathrm{mL}$ (Gibco, Paisley, UK), 2.5 mM L-glutamine (Lonza, Basel, Swiss), 15 mM HEPES (Gibco, Paisley, UK), $0.5 \mathrm{mM}$ sodium pyruvate (Sigma-Aldrich, Steinheim, Germany), and $1200 \mathrm{mg} / \mathrm{L}$ sodium bicarbonate (Gibco, Paisley, UK). The cells were cultured in a humidified environment at $28^{\circ} \mathrm{C}$ and with $5 \% \mathrm{CO}_{2}$. The cells were passaged every 3 to 4 days in a 1 to 3 ratio, using PBS (Medicago, Uppsala, Sweden) for washing and $0.25 \%$ trypsin (Sigma-Aldrich, Steinheim, Germany) for detachment.

Zebrafish liver cell line ZFL. Zebrafish liver cell line ZFL ${ }^{26,27}$ (CVCL_3276) was cultured in a medium consisting of $50 \%$ Leibovitz's L-15 (Sigma-Aldrich, Steinheim, Germany), 35\% Dulbecco's modified Eagle's medium (Gibco, Paisley, UK), 15\% Ham's Nutrient Mixture F-12 (Gibco, Paisley, UK), and phenol red. Additionally, $150 \mathrm{mg} / \mathrm{L}$ sodium bicarbonate (Gibco, Paisley, UK), $15 \mathrm{mM}$ HEPES (Gibco, Paisley, UK), $10 \mu \mathrm{g} / \mathrm{mL}$ bovine insulin (Sigma-Aldrich, Steinheim, Germany), $50 \mathrm{ng} / \mathrm{mL}$ mouse EGF (Sigma-Aldrich, Steinheim, Germany), and 5\% fetal bovine serum (Gibco, Paisley, UK) were supplemented. The cells were cultured in a humidified environment at $28^{\circ} \mathrm{C}$ and atmospheric $\mathrm{CO}_{2}$. The cells were passaged every 3 to 4 days in a 1 to 4 ratio, using PBS (Medicago, Uppsala, Sweden) for washing and 0.25\% Trypsin-EDTA (Sigma-Aldrich, Steinheim, Germany) for detachment.

Plasmid. The pGL4.37[luc2P/ARE/Hygro] plasmid was acquired from Promega, Madison, USA. The pGL4.37[luc2P/ARE/Hygro] vector consists of a pGL4 backbone including an ampicillin resistance gene, a gene for hygromycin resistance, and four copies of an Nrf2-sensitive antioxidant response element (ARE) driving transcription of the luciferase reporter gene luc2P (Photinus pyralis). A plasmid including the cDNA (Rluc) encoding Renilla luciferase reporter gene (Renilla reniformis) was used as a control of transfection efficiency and for normalization.

Chemicals. The following chemicals were used for exposure studies: atrazine (CAS 1912-24-9), 99.3\% purity, Dr. Ehrenstorfer GmbH, Augsburg, Germany; deltamethrin (CAS 52918-63-5), 99.5\% purity, Dr. Ehrenstorfer GmbH, Augsburg, Germany; diazinon (333-41-5), 99\% purity, Dr. Ehrenstorfer GmbH, Augsburg, Germany; Dimethyl sulfoxide (CAS 67-68-5), 99.9\% purity, Sigma-Aldrich, St. Louis, USA; diuron (CAS 330-54-1), 98.8\% purity, Dr. Ehrenstorfer $\mathrm{GmbH}$, Augsburg, Germany; hydrogen peroxide $\left(\mathrm{H}_{2} \mathrm{O}_{2}\right)(\mathrm{CAS} 7722-84-1)$, Sigma-Aldrich, Steinheim, Germany; metazachlor (CAS 67129-08-2), 99.5\% purity, Dr. Ehrenstorfer GmbH, Augsburg, Germany; sulforaphane (SFN) (CAS 4478-93-7), 90\% purity, Sigma-Aldrich, Steinheim, Germany; terbutylazine (tBA) (CAS 5915-41-3), 99.5\% purity, Dr. Ehrenstorfer GmbH, Augsburg, Germany; tertbutylhydroquinone (tBHQ) (CAS 1948-33-0), 97\% purity, Sigma-Aldrich, St. Louis, USA.

The compounds were dissolved in $20 \mathrm{mM}$ stock solutions of atrazine, deltamethrin, diazinon, diuron, metazachlor, and terbutylazine in $99 \% \mathrm{EtOH}$ and stored at $-20^{\circ} \mathrm{C}$. Stock solutions of $\mathrm{H}_{2} \mathrm{O}_{2}$ and tBHQ of $100 \mathrm{mM}$ were prepared in $99 \% \mathrm{EtOH}$ and stored at $-20^{\circ} \mathrm{C}$ for every new experiment. A $50 \mathrm{mM}$ stock of SFN in $99 \% \mathrm{EtOH}$ was prepared and stored at $-80^{\circ} \mathrm{C}$.

Dual reporter gene assay. Transfection of zebrafish cell lines. Twelve commercially available transfection reagents: TransIT-X2 ${ }^{\circledR}$, TransIT $^{\circledR}$-LT1, TransIT ${ }^{\circledR}-2020$ (Mirus, Madison, USA); FuGENE ${ }^{\circledR}$ HD (FHD), FuGENE ${ }^{\circledR}$ 6, ViaFect ${ }^{\mathrm{TM}}$, TransFast ${ }^{\mathrm{TM}}$ (Promega, Madison, USA); X-tremeGENE HP (XHP) (Roche, Mannheim, Germany); Lipofectamine $^{\circledR} 2000$ (Invitrogen, Carlsbad, USA); SuperFect ${ }^{\circledR}$, Effectene $^{\circledR}$ (Qiagen, Hilden, Germany); jetPRIME ${ }^{\circledR}$ (Polyplus, Illkirch-Graffenstaden, France) were tested for suitability to zebrafish cells and maximal induced transfection efficiency. Cells of all three mentioned cell lines were seeded at a density of $10^{4}$ cells/well in white, clear-bottom 96-well plates (Corning, New York, USA) in $100 \mu \mathrm{l} /$ well. After $24 \mathrm{~h}$ incubation at above stated conditions, cells were transiently 
transfected with the Renilla plasmid only. Varying reagent to DNA mass ratios were applied in quadruplicates according to the manufacturer's instructions. Mirus, Promega, Roche, and Invitrogen derived reagents were applied in a $1 \mu \mathrm{g}$ DNA to 2,4 , or $6 \mu \mathrm{g}$ reagent mass ratio, SuperFect in a $1 \mu \mathrm{g}$ DNA to 1,5 , or $10 \mu \mathrm{g}$ reagent mass ratio, Effectene in a $1 \mu \mathrm{g}$ DNA to 10,25 , or $50 \mu \mathrm{g}$ reagent mass ratio and jetPrime in a $1 \mu \mathrm{g}$ DNA to 1,2 , or $3 \mu \mathrm{g}$ reagent mass ratio. Total background Renilla luciferase induction for the single ratios in comparison to solvent control was considered as the benchmark. Subsequently, for most promising candidates, series of different cell concentrations $\left(10^{3}\right.$ cells/well, $5^{*} 10^{3}$ cells/well, $10^{4}$ cells/well, $5^{*} 10^{4}$ cells/well, $10^{5}$ cells/well, $5^{*} 10^{5}$ cells/well in $100 \mu \mathrm{l} /$ well) were prepared and transiently transfected at the optimal ratio, in order to determine the best DNA-reagent-ratio to cell-density parameters. Induced background luminescence was scored identically to procedures described in the following section, with the only difference that a single luminescence signal was required.

Nrf2-responsive assay. Above mentioned cell lines were transiently co-transfected with the pGL4.37[luc2P/ ARE/Hygro] plasmid and the Renilla plasmid using FHD (Promega, Madison, USA) for Pac2 and ZF4, and XHP (Roche, Mannheim, Germany) for ZFL. Subsequently, after exposure to known Nrf2 inducers or pesticides, Nrf2 induction was analyzed using a Dual-Luciferase ${ }^{\circledR}$ Reporter $\left(D_{L} R^{\mathrm{TM}}\right)$ assay (Promega, Madison, USA). Cells were seeded into white, clear-bottom 96-well plates (Corning, New York, USA) at a density of $10^{4}$ cellls/well for Pac2, $1.25^{*} 10^{4}$ cells/well for ZF4, and $2.5^{*} 10^{4} \mathrm{cells} /$ well for ZFL in $100 \mu \mathrm{l} /$ well. After $24 \mathrm{~h}$ of incubation, cells reached a confluency of about $80 \%$. Transient transfection using FHD or XHP, respectively was conducted in a $2 \mu \mathrm{g}$ reagent to $1.2 \mu \mathrm{g}$ DNA $(0.9 \mu \mathrm{g}$ reporter plasmid, $0.3 \mu \mathrm{g}$ control plasmid) ratio, according to the manufacturer's instructions. After $24 \mathrm{~h}$ of post-transfection incubation, cells were exposed to postulated Nrf2 inducers or pesticides. Prepared stock solutions (see section "Chemicals") were further diluted using the cell type specific nutrition medium (see section "Cell culture") supplemented with 5\% EtOH as a solvent. Seeded cells on 96-well plates were either exposed in technical quadruplicates to increasing concentrations $(0.1 \mu \mathrm{M}, 1 \mu \mathrm{M}, 10 \mu \mathrm{M}, 100 \mu \mathrm{M})$ of postulated $\mathrm{Nrf} 2$ inducers tBHQ, SFN, and $\mathrm{H}_{2} \mathrm{O}_{2}$ or to increasing concentrations $(6.25 \mu \mathrm{M}, 12.5 \mu \mathrm{M}, 25 \mu \mathrm{M}, 50 \mu \mathrm{M}$, $100 \mu \mathrm{M})$ of the pesticides atrazine, deltamethrin, diazinon, diuron, metazachlor, and terbutylazine. Double quadruplicates of 5\% EtOH solvent-nutrition medium were used as controls. In parallel with the oxidative stress exposure, increasing DMSO concentrations $(1 \%, 4 \%, 7 \%$, and $10 \% \mathrm{v} / \mathrm{v})$ were tested as a cytotoxic control. After $24 \mathrm{~h}$ incubation, cells were lysed and quantitative Nrf2-dependent luminescence was measured via Dual-Luciferase ${ }^{\circledR}$ Reporter assay according to the manufacturer's protocol using an auto-injecting Infinite M1000 microplate reader (Tecan, Männedorf, Switzerland). The luciferase activity was expressed as fold change compared to the controls.

Cell viability testing. In order to determine cytotoxic concentrations of used compounds within the exposure range, cell viability was examined using an MTS-based [3-(4,5-dimethylthiazol-2-yl)-5-(3-carb oxymethoxyphenyl)-2-(4-sulfophenyl)-2 H-tetrazolium] CellTiter $96^{\circledR}$ AQueous One Solution Cell Proliferation Assay (Promega, Madison, USA) in accordance with the manufacturer's protocol. Viability tests were conducted in parallel to the dual reporter gene assays, applying the same arrangements and exposure set-ups. Cells were seeded in transparent 96-well plates (Corning, New York, USA) and transient transfection was omitted. Simultaneously to transfected cells being lysed for scoring of luminescence signal, nutrition medium of cells being used in viability test was discharged and replaced by PBS containing 17\% (v/v) MTS-reagent. After $2 \mathrm{~h}$ of incubation, formazan product turnover absorbance was measured at $490 \mathrm{~nm}$ using a Wallac Victor2 1420 microplate reader (PerkinElmer, Massachusetts, USA). Relative effects on cell viability were calculated in relation to the vehicle control.

Statistical analyses. Results from the dual luciferase assay and the viability assay were processed using R and GraphPad Prism 7 (GraphPad Software, La Jolla, USA). Graphs and illustrations were designed using GraphPad Prism 7. For both assays data of three or four experiments (experimental unit $n=3-4$ ), each performed with quadruplicate samples for each concentration, were pooled and log-transformed to achieve homoscedasticity, giving a total population size for every exposure group of 10-16 (observational unit $\mathrm{N}=10-16$ ). Data was normalized against internal background within the dual reporter gene assay and against the negative control, giving fold induction as a final output. Significant differences between the control and the exposure groups were analyzed via a mixed-model two way-ANOVA followed by Dunnett's post-hoc test ${ }^{28}$. Thereby, transformed output data was considered as a fixed factor whereas experiments were considered as a random factorial factor within the model in order to account for inter-experimental variation. A p $<0.05$ was considered statistically significant. Normality (quantile-quantile-plot) and homoscedasticity (residuals-vs.-fitted) of data sets were checked via graphical analysis of residuals.

\section{Results}

Transfection efficiency of various commercial reagents in zebrafish cell lines. Establishment of transgenic cell lines requires knowledge on transfection efficiency of different available transfection reagents for specific cell lines. Most commercially available transfection reagents are developed for transfection of mammalian cells. We have therefore tested the transfection efficiency of twelve commercially available transfection reagents in all three zebrafish cell lines (see supplementary data). The cells were transfected with a Renilla luciferase plasmid in different reagent to DNA mass ratios, according to the manufacturer's instructions. The total Renilla luminescence was analyzed as a measurement of transfection efficiency. Additionally, increasing cell densities were tested in the best detected DNA to transfection reagent ratios (data not shown). The following transfection parameters were found to result in the highest transfection efficiency for Pac2, ZF4 and ZFL, respectively: Pac2, plating density of $10^{4}$ cells/well and a $4 \mu \mathrm{g}$ FHD to $1 \mu \mathrm{g}$ DNA ratio (Fig. S1). ZF4, plating density of $1.25^{*} 10^{4}$ cells/well and a $2 \mu \mathrm{g}$ FHD to $1 \mu \mathrm{g}$ DNA ratio (Fig. S2). ZFL, plating density of $2.5^{*} 10^{4}$ cells/well and a $2 \mu \mathrm{g}$ XHP to $1 \mu \mathrm{g}$ DNA ratio 

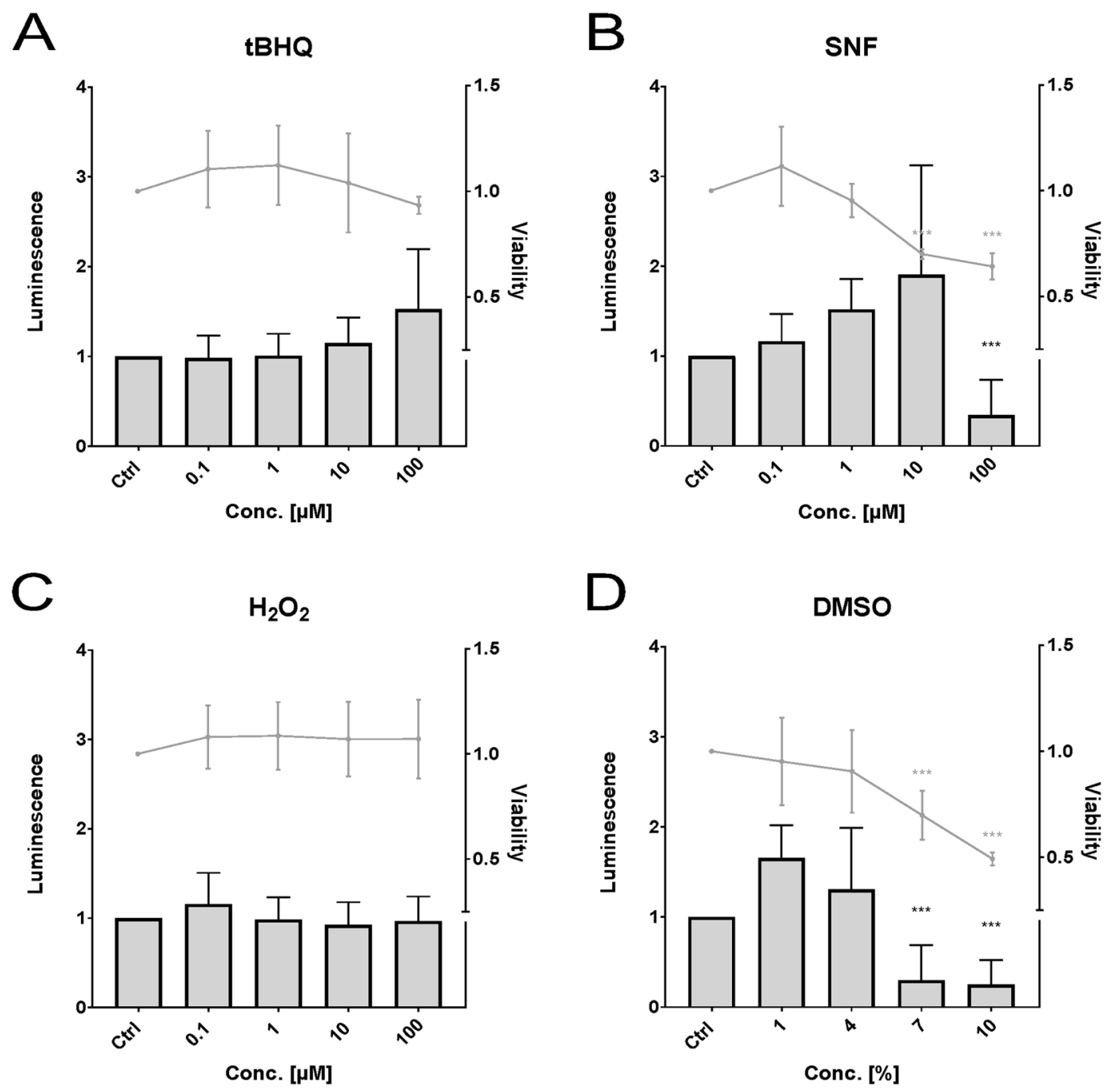

Figure 1. Effects of tertbutylhydroquinone (A, "tBHQ"), sulforaphane (B, "SFN"), hydrogen peroxide (C), and dimethyl sulfoxide (D, "DMSO") on luminescence (bars) and viability (lines) measured in the zebrafish cell line Pac2. Luminescence corresponds to quantitative Nrf2 activation measured via dual reporter gene assay. Viability corresponds to measured absorbance of formazan product via MTS-assay. Each bar and point respectively represent the mean (experimental units $\mathrm{n}=3-4$; observational units $\mathrm{N}=10-16$ ) including $\mathrm{SD}$. Asterisks indicate significance tested in a two-way ANOVA mixed model with Dunett's post-hoc test $(* * * \mathrm{p}<0.001$; grey $=$ viability; black = luminescence).

or jetPRIME in a 3 to 1 ratio (Fig. S3). Finally, FHD for the Pac2 and ZF4 and XHP for the ZFL cell lines were chosen for further experiments .

Activation of Nrf2 and cell viability in zebrafish cell lines. All three zebrafish cell lines were co-transfected with an Nrf2-responsive Firefly-luciferase plasmid and a normalizing Renilla-luciferase plasmid. In order to quantify cell line specific responses, cells were exposed to known or postulated Nrf2 inducers tBHQ, $\mathrm{SFN}$, and $\mathrm{H}_{2} \mathrm{O}_{2}$ in concentrations of 0.1 to $100 \mu \mathrm{M}$ for $24 \mathrm{~h}$. DMSO was used as a cytotoxic control. In parallel to detecting Nrf2-activation via the dual reporter gene assays, cell viability was measured within the same experimental set-up using the MTS-assay.

In the Pac2 cell line (Fig. 1) there was no statistically significant increase in Nrf2 activity by any of the tested compounds. Statistically significant decrease in activity was observed for SFN (Fig. 1B) at a concentration of $100 \mu \mathrm{M}$ and for DMSO (Fig. 1D) at 7\% and 10\%. Statistically significantly reduced cell viability was observed at 10 and $100 \mu \mathrm{M}$ for SFN and at $7 \%$ and $10 \%$ for DMSO.

In the ZF4 cell line (Fig. 2) statistically significant induction of the Nrf2 activity was observed for tBHQ (Fig. 2A) at 10 (2.3-fold) and $100 \mu \mathrm{M}$ (7.2-fold) and for SFN (Fig. 2B) at $10 \mu \mathrm{M}$ (3-fold). Statistically significant decrease in activity was observed for SFN (Fig. 2B) at a concentration of $100 \mu \mathrm{M}$ and for DMSO (Fig. 2D) at 7\% and $10 \%$. Significant cytotoxicity was detected for DMSO within all tested concentrations, for SFN at a concentration of $10 \mu \mathrm{M}$ and $100 \mu \mathrm{M} . \mathrm{H}_{2} \mathrm{O}_{2}$ (Fig. 2C) did not alter the Nrf2 activity nor the cell viability. 
A

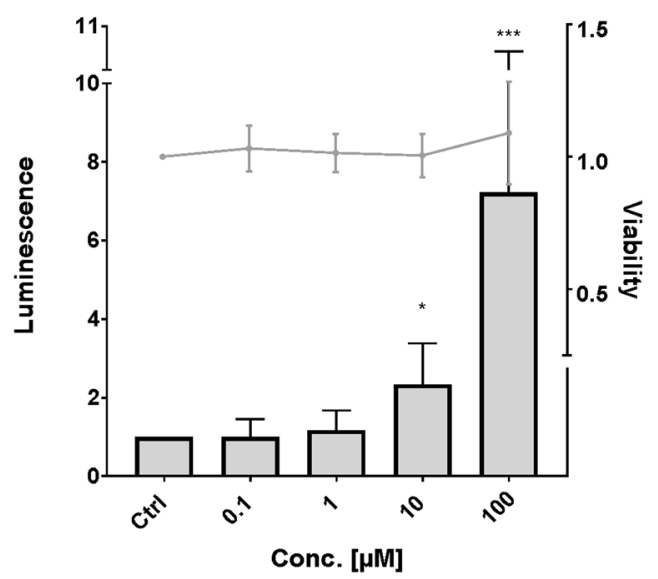

C

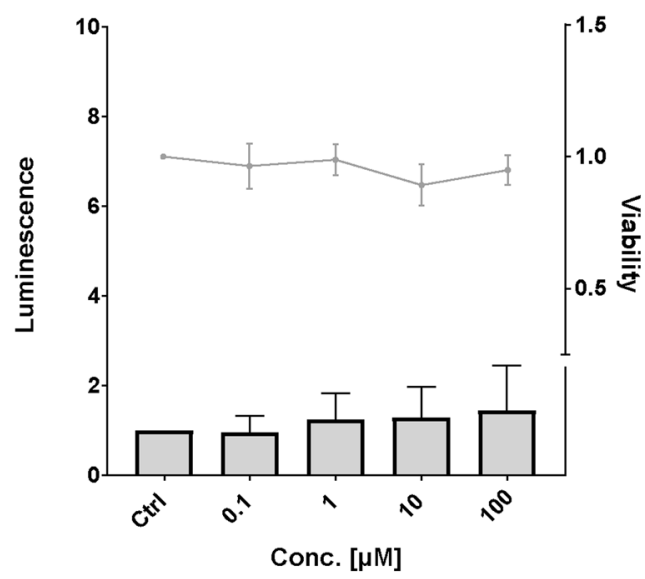

B SFN

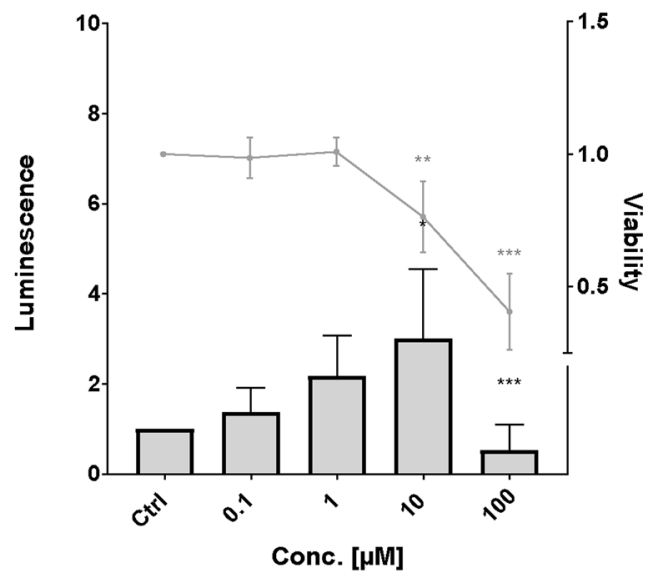

DMSO

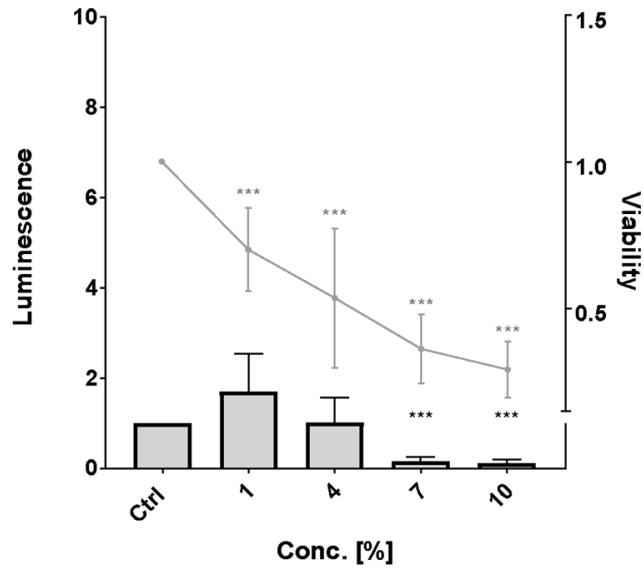

Figure 2. Effects of tertbutylhydroquinone (A, "tBHQ"), sulforaphane (B, "SFN"), hydrogen peroxide (C), and dimethyl sulfoxide (D, "DMSO") on luminescence (bars) and viability (lines) measured in the zebrafish cell line ZF4. Luminescence corresponds to quantitative Nrf2 activation measured via dual reporter gene assay. Viability corresponds to measured absorbance of formazan product via MTS-assay. Each bar and point respectively represent the mean (experimental units $\mathrm{n}=3-4$; observational units $\mathrm{N}=10-16$ ) including $\mathrm{SD}$. Asterisks indicate significance tested in a two-way ANOVA mixed model with Dunett's post-hoc test $\left({ }^{*} \mathrm{p}<0.05\right.$, $* * \mathrm{p}<0.01, * * * \mathrm{p}<0.001$; grey $=$ viability; black = luminescence) .

In the ZFL cell line (Fig. 3) statistically significant activation of Nrf2 was observed for tBHQ (Fig. 3A) at a concentration of $10 \mu \mathrm{M}$ (2.8-fold), for SFN (Fig. 3B) also at $10 \mu \mathrm{M}$ (4.7-fold), and for DMSO (Fig. 3D) at $1 \%$ (3.2-fold). Statistically significant decrease in activity was observed for tBHQ and SFN at $100 \mu \mathrm{M}$ and for DMSO at $7 \%$ and $10 \%$. SFN showed statistically significant cytotoxicity at 10 and $100 \mu \mathrm{M}, \mathrm{tBHQ}$ at $100 \mu \mathrm{M}$, and DMSO at all concentrations. For $\mathrm{H}_{2} \mathrm{O}_{2}$ (Fig. 3C), no statistically significant change in Nrf2 activity was observed, although at $10 \mu \mathrm{M}$ and at $100 \mu \mathrm{M}$ a slight cytotoxicity was detected.

Activation of Nrf2 by pesticides. The cell lines ZF4 and ZFL showed a higher sensitivity to the tested positive controls (section 3.2), as compared to the Pac2 cell line. Therefore, the latter was not further tested since in addition fibroblast-like cells were already covered by ZF4. To test the applicability of the assay, ZF4 and ZFL cells transfected with the Nrf2 sensitive luciferase plasmid were used to investigate the potential oxidative stress potency of six pesticides.

In the ZF4 cell line, we found that the Nrf2 activity was significantly increased by the pesticides deltamethrin (Fig. 4B) at $50 \mu \mathrm{M}$ (3.2-fold) and $100 \mu \mathrm{M}$ (5-fold), diazinon (Fig. 4C) at $100 \mu \mathrm{M}$ (4.1-fold), and metazachlor (Fig. $4 \mathrm{E}$ ) at $50 \mu \mathrm{M}$ (4-fold) and $100 \mu \mathrm{M}$ (5.7-fold). No effects on the Nrf2 activity were observed after atrazine, diuron and terbutylazine exposure (Fig. 4A). No cytotoxicity was observed for any of the pesticides.

In the ZFL cell line, statistically significant Nrf2 activation was observed for diuron (Fig. 5D) (2.8- fold) at $100 \mu \mathrm{M}$ and for metazachlor (Fig. 5E) at $12.5 \mu \mathrm{M}$ (2.9-fold), $25 \mu \mathrm{M}$ (5.5-fold), $50 \mu \mathrm{M}$ (6.6-fold), and $100 \mu \mathrm{M}$ (9.3-fold). Atrazine (Fig. 5A), deltamethrin (Fig. 5B), diazinon, and terbutylazine did not induce any effects, 
A

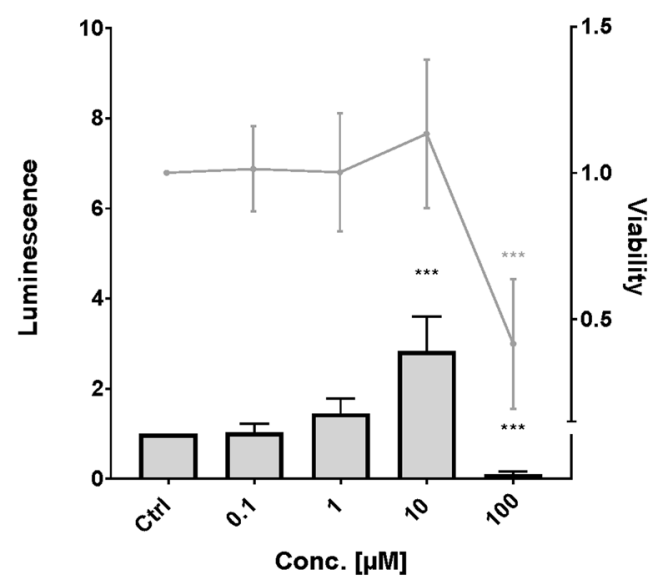

C

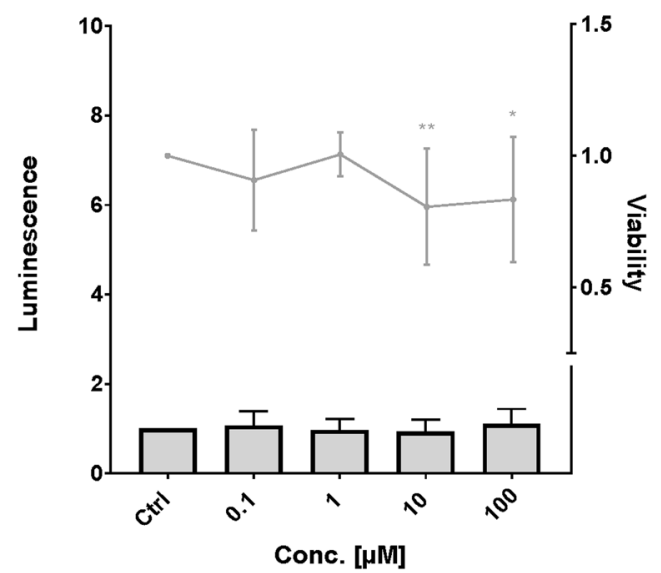

B

SFN

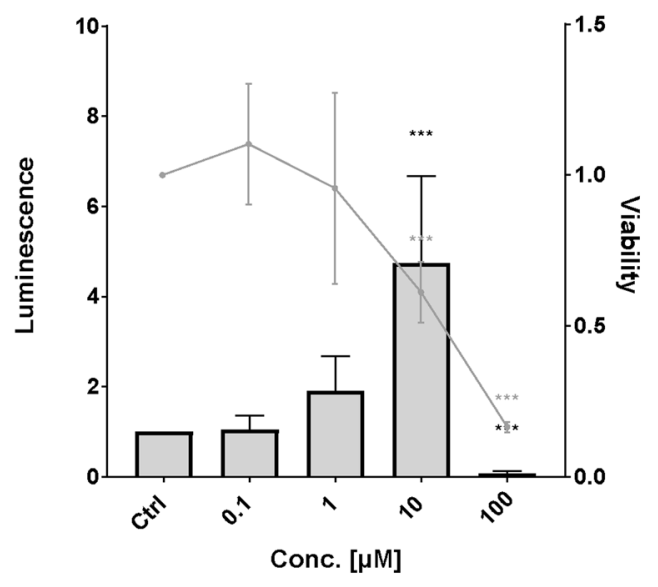

DMSO

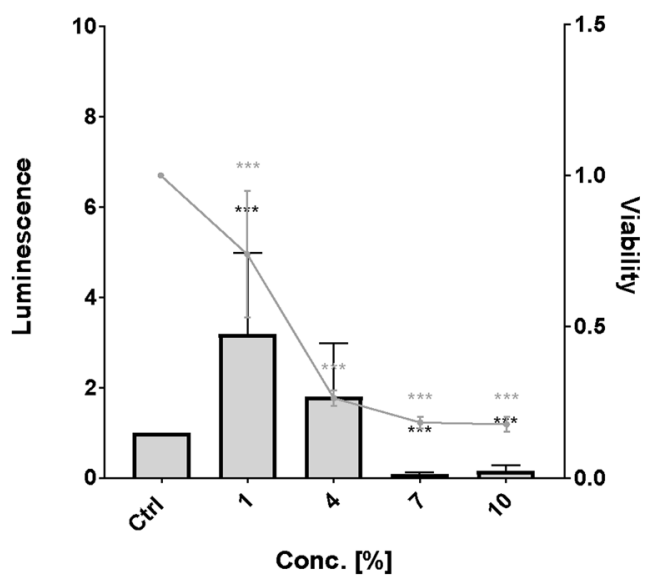

Figure 3. Effects of tertbutylhydroquinone (A, "tBHQ"), sulforaphane (B, "SFN"), hydrogen peroxide (C), and dimethyl sulfoxide (D, "DMSO") on luminescence (bars) and viability (lines) measured in the zebrafish cell line ZFL. Luminescence corresponds to quantitative Nrf2 activation measured via dual reporter gene assay. Viability corresponds to measured absorbance of formazan product via MTS-assay. Each bar and point respectively represent the mean (experimental units $\mathrm{n}=3-4$; observational units $\mathrm{N}=10-16$ ) including $\mathrm{SD}$. Asterisks indicate significance tested in a two-way ANOVA mixed model with Dunett's post-hoc test $(* \mathrm{p}<0.05, * * \mathrm{p}<0.01$, $* * * \mathrm{p}<0.001$; grey = viability; black = luminescence).

neither on the Nrf2 activity nor the cell viability. A statistically significant decrease in viability was observed for metazachlor at $100 \mu \mathrm{M}$, while all other groups showed no effects on cell viability.

\section{Discussion}

The Keap1-Nrf2-ARE signaling pathway is a major balancer of oxidative homeostasis, given its role in oxidative stress response but also physiological regulation ${ }^{29}$. Oxidative stress may lead to toxicity e.g. via enzyme deactivation, lipid peroxidation, and DNA damage. These effects may lead to tissue damage, apoptosis or cell necrosis ${ }^{1,30}$ and further to developmental toxicity ${ }^{31,32}$ and cancer ${ }^{33}$. So far, in vivo methods for determination of Nrf2 activity have been established in zebrafish strains ${ }^{34-36}$, in vitro methods using mammalian cells are described ${ }^{37-40}$, and standardized high-throughput assays in human cell lines ${ }^{41}$ have been developed. Here, we report the development of a reporter gene assay for oxidative stress response in zebrafish cell lines.

Transfection efficiency. In this study, we have tested the transfection efficiency of twelve commercially available transfection reagents in three different cell lines and found a high variability in efficiency between the transfection reagents. We found that FuGENE HD (Promega) showed the highest transfection efficiency in both Pac2 and ZF4, while X-tremeGENE HP (Roche) and jetPRIME (Polyplus) showed the highest transfection efficiency in ZFL. These are important findings for future efforts to establish in vitro assays using transfected zebrafish cell lines. 
A

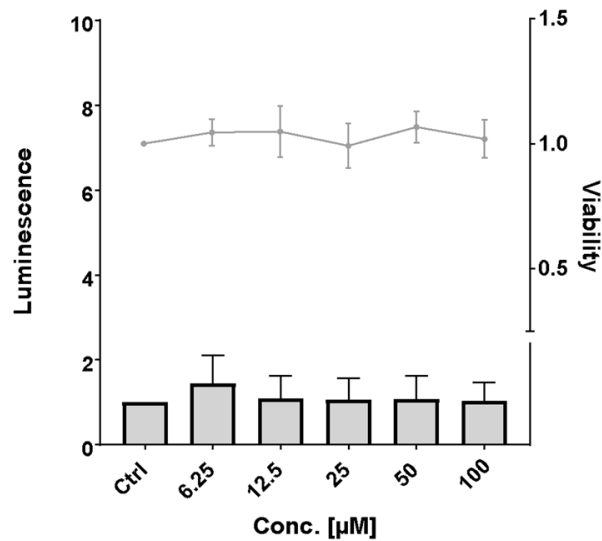

C

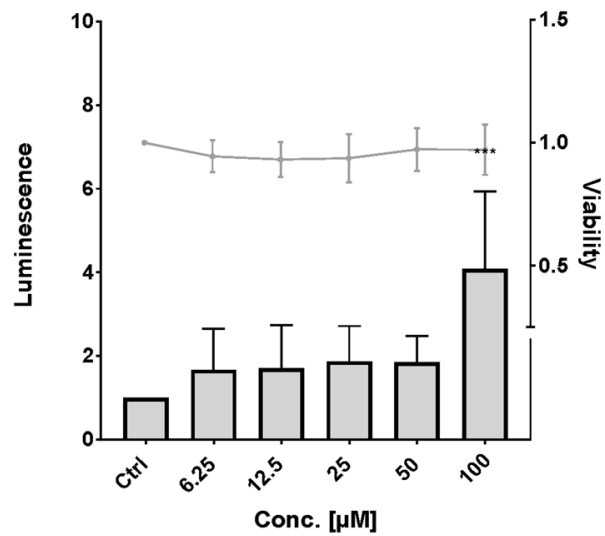

E

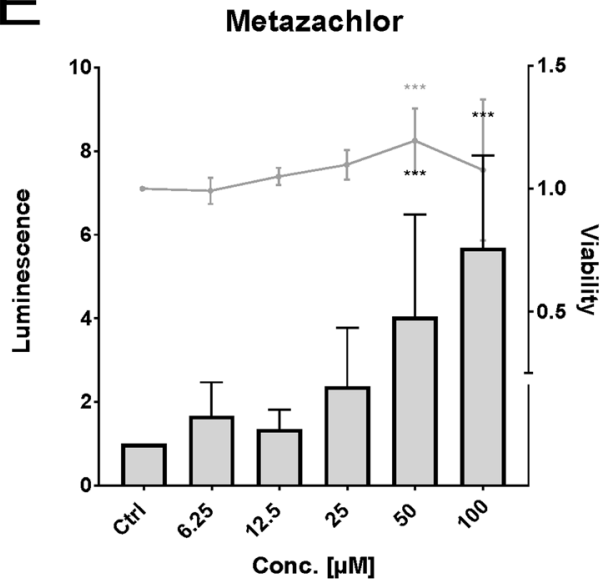

B

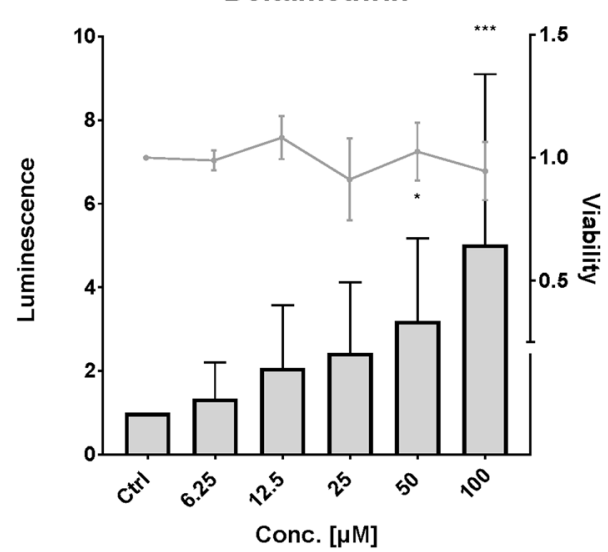

$\mathrm{D}$

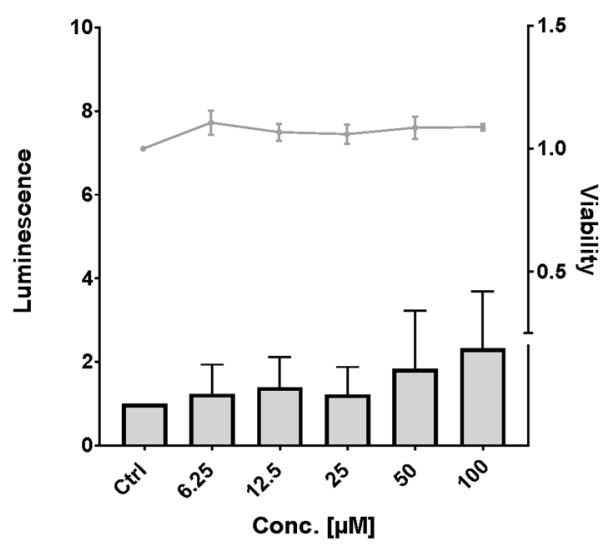

$\mathrm{F}$

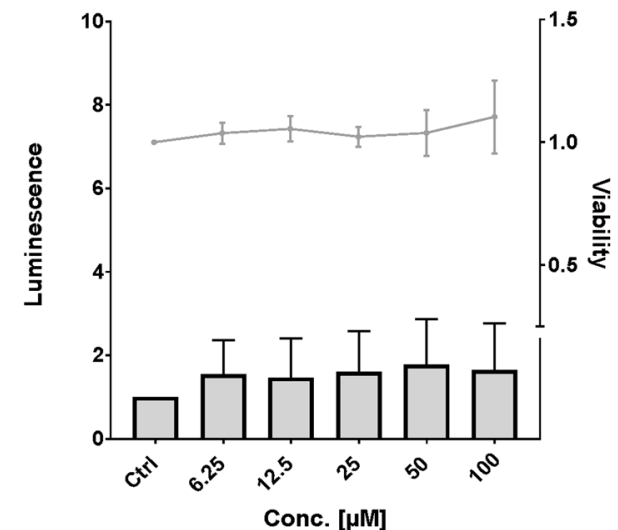

Figure 4. Effects of the pesticides atrazine (A), deltamethrin (B), diazinon (C), diuron (D), metazachlor (E), and terbutylazine (F, "tBA") on luminescence (bars) and viability (lines) measured in the zebrafish cell line ZF4. Luminescence corresponds to quantitative Nrf2 activation measured via dual reporter gene assay. Viability corresponds to measured absorbance of formazan product via MTS-assay. Each bar and point respectively represent the mean (experimental units $\mathrm{n}=3-4$; observational units $\mathrm{N}=10-16$ ) including SD. Asterisks indicate significance tested in a two-way ANOVA mixed model with Dunett's post-hoc test $\left({ }^{*} \mathrm{p}<0.05\right.$, $* * * \mathrm{p}<0.001$; grey = viability; black = luminescence).

The oxidative stress response varies within different zebrafish cell lines. We have analyzed the Nrf2 activity in three zebrafish cell lines; Pac2, ZF4 and ZFL. The Pac2 and ZF4 cell lines are pooled embryonic fibroblasts, whereas the ZFL cell line was established from hepatocytes derived from a single adult individual. In this way, different developmental stages and tissue types are represented in the study. Hepatocytes were chosen since the liver 
A

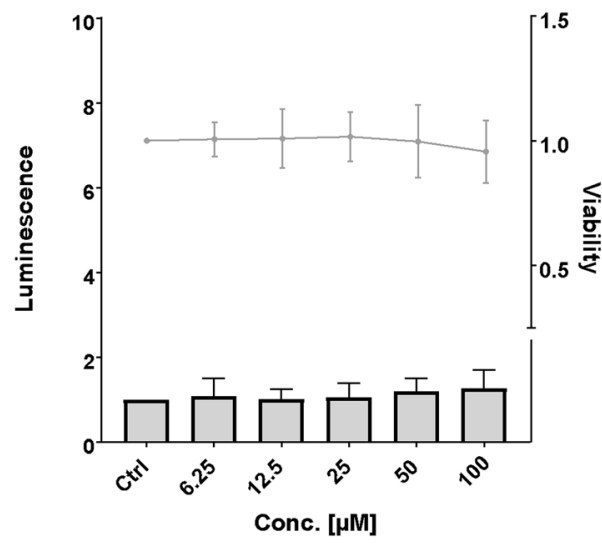

C

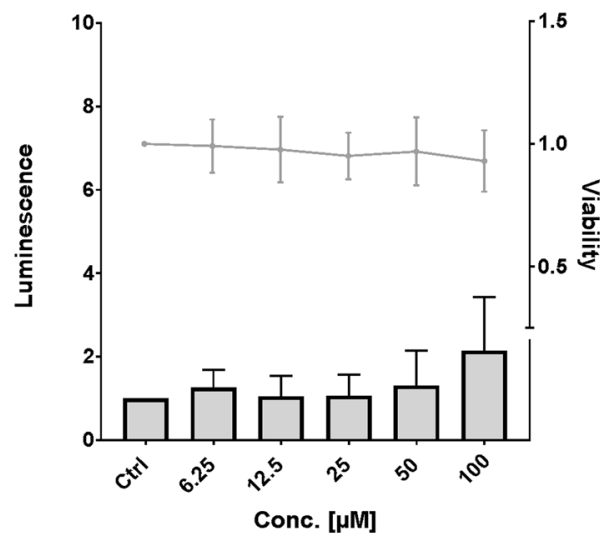

E

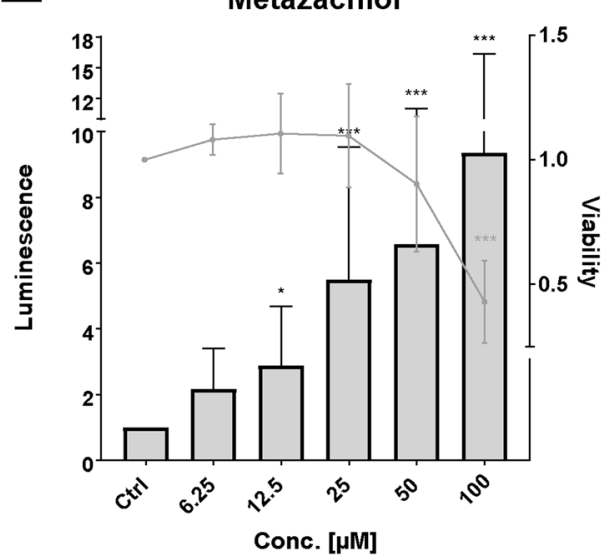

B

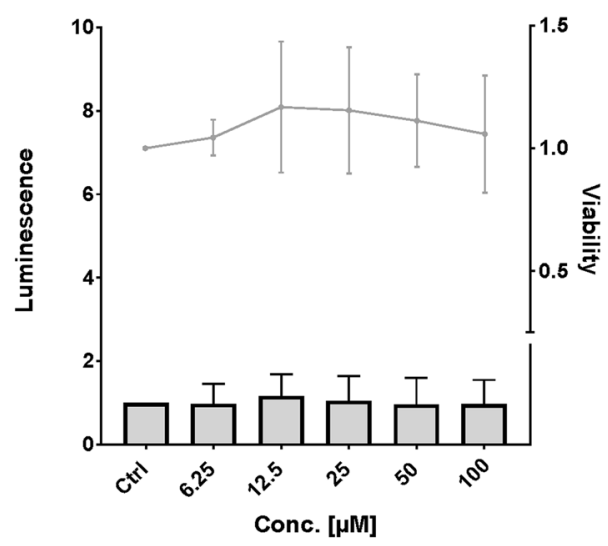

D

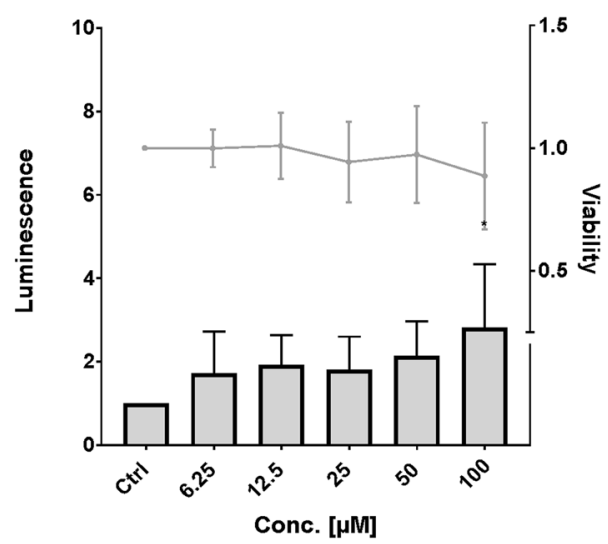

tBA

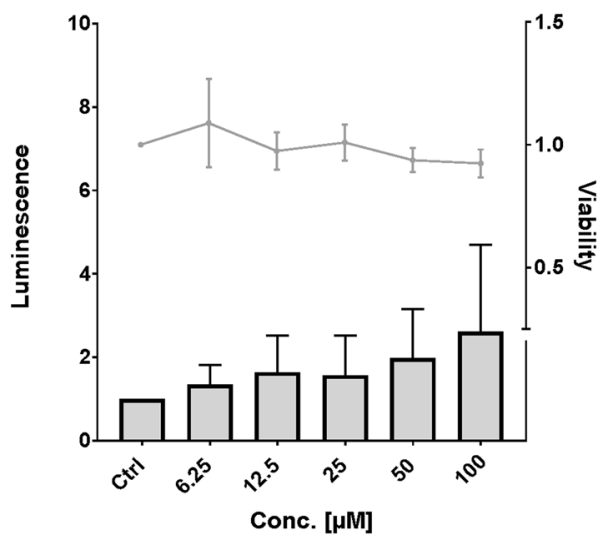

Figure 5. Effects of the pesticides atrazine (A), deltamethrin (B), diazinon (C), diuron (D), metazachlor (E), and terbutylazine ((F, "tBA") on luminescence (bars) and viability (lines) measured in the zebrafish cell line ZFL. Luminescence corresponds to quantitative Nrf2 activation measured via dual reporter gene assay. Viability corresponds to measured absorbance of formazan product via MTS-assay. Each bar and point respectively represent the mean (experimental units $\mathrm{n}=3-4$; observational units $\mathrm{N}=10-16$ ) including SD. Asterisks indicate significance tested in a two-way ANOVA mixed model with Dunett's post-hoc test $\left({ }^{*} \mathrm{p}<0.05\right.$, $* * * \mathrm{p}<0.001$; grey = viability; black = luminescence).

is the primary location of detoxification and show highest abundancy in critical phase II enzymes, such as GSTs ${ }^{42}$. In order to test single cell line feasibility, each transfected cell line was first exposed to postulated Nrf2 inducers. The results showed that the Nrf2 activity following exposure varied between cell lines. The Keap1-Nrf2-ARE signaling pathway is not functional immediately after fertilization and the responsiveness to oxidative stress seems to 
vary during embryogenesis and larval development ${ }^{32,43,44}$. Within $24 \mathrm{hpf}$, the response to oxidative stress or Nrf2 inducers is quite low, increases up to $48 \mathrm{hpf}$, exhibits high variability during hatching and post-hatching, and finally stabilizes at around $96 \mathrm{hpf}$. This could be an explanation for the observed differences in sensitivity between the three investigated cell lines, as they are derived from zebrafish in different developmental stages. In addition, an impact of total serum concentration in the culture medium and therefore less available, non-protein bound compound concentration could be an alternative explanation for the differences in response between these zebrafish cell lines. Pac2 cells are cultured at a higher serum concentration (15\%) than ZF4 and ZFL cells (10 and 5\% respectively), which might explain the observed differences in sensitivity. Since Nrf2 is ubiquitously expressed in most cell types and acts via a common mechanism, its activity is generally only assayed in a single cell type when using bioassays based on mammalian cells ${ }^{45-47}$. However, our result show that cell line selection is crucial for this assay and further research is needed to fully explain the observed differences in oxidative stress sensitivity in zebrafish cell lines.

$\mathrm{H}_{2} \mathrm{O}_{2}$ does not activate Nrf2 in zebrafish cell lines. Surprisingly, we were unable to show an Nrf2 induction by $\mathrm{H}_{2} \mathrm{O}_{2}$ in any of the cell lines studied, although $\mathrm{H}_{2} \mathrm{O}_{2}$ is normally metabolized by GSTs which are $\mathrm{Nrf2}$ regulated. However, Nrf2-recruitment failure by $\mathrm{H}_{2} \mathrm{O}_{2}$ has previously been described during development in embryos $^{35,48,49}$ and in larvae ${ }^{36}$. The phenomenon is either interpreted as a systemic breakdown of the Nrf2-Keap1 axis $^{48}$ or absence of an intermediate "posthatch factor" which is induced by $\mathrm{H}_{2} \mathrm{O}_{2}$ and then modulates the Nrf2 response $\mathrm{s}^{35}$. On the contrary, $\mathrm{Nrf} 2$ induction by $\mathrm{H}_{2} \mathrm{O}_{2}$ was reported in mammalian cell lines ${ }^{50}$. Species differences, methodological aspects, since $\mathrm{H}_{2} \mathrm{O}_{2}$ is a very reactive compound with short half-life, and interactions with media components may partly explain why we did not see any $\mathrm{Nrf} 2$ induction by $\mathrm{H}_{2} \mathrm{O}_{2}$.

Application of an Nrf2 responsive reporter gene assay. To test the potential application of the established assay, six pesticides suspected to cause oxidative stress ${ }^{22}$ were analyzed. We found that four out of the six analyzed compounds significantly increased the Nrf2 activity in at least one cell line. The dose-effect relationship for the compounds differed, where some compounds showed a clear dose-dependent increase in the Nrf2 activity, while other compounds showed a threshold-like effect with an increased Nrf2 activity only observed within the highest exposure concentration. However, those compounds would need to be tested at higher, non-toxic concentrations in order to exclude dose-dependency. These different patterns may be explained by differing mechanisms by which the compounds are inducing the Nrf2 release from Keap1 and thereby trigger the oxidant stress response. Such a mechanism-related model has been proposed by Kobayashi, Yamamoto, and co-workers ${ }^{9,35,51,52}$.

It has been reported that deltamethrin is causing alterations in antioxidant enzymes (glutathione S-transferase (GST), superoxide dismutase (SOD), catalase (CAT), glutathione peroxidase (GPx), and glutathione reductase (GR)), reduced glutathione concentration levels (GSH), and lipid peroxidation levels (LPO) in Prussian carp (Carassius gibelio) $^{53,54}$, spotted snakehead (Channa punctata) ${ }^{55,56}$, carp (Cyprinus carpio) ${ }^{57}$, and bushynose (Ancistrus multispinis $)^{58}$, whereas other species did not show a similar response to deltamethrin ${ }^{59}$. We report an effect in ZF4, but no effects were observed in ZFL. Deltamethrin is primarily metabolized by phase I enzymes CYP1A1, CYP1A2, and carboxylesterases ${ }^{60,61}$. The lack of effect in the ZFL cell line may therefore be due to a faster metabolism of the compound within hepatocytes, since functional phase I activity has been reported in vitro $0^{27,62,63}$ on transcript and protein levels, although also other mechanisms might explain the observed difference in response in ZFL and ZF4. Alterations in antioxidant enzymes, GSH, and LPO levels have also been reported in carp (Cyprinus carpio) after exposure to diazinon ${ }^{64,65}$. Beyond that, histopathological endpoints had been identified in bluegill sunfish (Lepomis macrochirus $)^{66}$. Diuron has been reported to induce oxidative stress after chronic exposure to goldfish (Carassius auratus ${ }^{67}$, alternating GST and CAT levels in tropical fish (Astyanax sp. $)^{68}$, and genotoxicity in rainbow trout liver and gill cell lines (RTL-W1, RTG-W1) ${ }^{69}$. An induced Nrf2 activity by diuron and diazinon has also been reported in human liver hepatoma cell line (HepG2) at comparable concentrations ${ }^{11}$. Metazachlor was the most potent inducer of Nrf2 activity, showing a higher potency than the known inducers used as positive controls. No studies on oxidative stress response by metazachlor were found in the literature. However, regulatory toxicity testing has demonstrated low acute toxicity in rainbow trout (Oncorhynchus mykiss), carp, and bluegill sunfish ${ }^{70}$. In mammals limited evidence of carcinogenic effects has been reported besides acute toxicity ${ }^{71}$. To our knowledge, this is a novel finding on the toxicity of metazachlor in vertebrates and prompts further investigation regarding the toxicity of metazachlor.

\section{Conclusion}

We describe the development and application of a novel Nrf2 responsive reporter gene assay to monitor oxidative stress response in various zebrafish cell lines. Further, we have shown that the developed assay is useful for chemical testing by analyzing the effect of postulated Nrf2 inducers and compounds which were suggested to induce oxidative stress in fish. We suggest that this model could be a valuable tool for future research in aquatic toxicology to study the toxicity of both pure compounds and environmental samples.

Data availability. The datasets generated during the current study are available from the corresponding author upon request.

\section{References}

1. Nikinmaa, M. An Introduction to Aquatic Toxicology. (Elsevier Science \& Technology, 2014).

2. Itoh, K., Tong, K. I. \& Yamamoto, M. Molecular mechanism activating Nrf2-Keap1 pathway in regulation of adaptive response to electrophiles. Free Radic. Biol. Med. 36, 1208-13 (2004).

3. Rushmore, T. H., Morton, M. R. \& Pickett, C. B. The antioxidant responsive element. Activation by oxidative stress and identification of the DNA consensus sequence required for functional activity. J. Biol. Chem. 266, 11632-9 (1991).

4. Wasserman, W. W. \& Fahl, W. E. Functional antioxidant responsive elements. Proc. Natl. Acad. Sci. USA 94, 5361-6 (1997),

5. Köhle, C. \& Bock, K. W. Coordinate regulation of Phase I and II xenobiotic metabolisms by the Ah receptor and Nrf2. Biochem. Pharmacol. 73, 1853-62 (2007). 
6. Itoh, K., Ishii, T., Wakabayashi, N. \& Yamamoto, M. Regulatory mechanisms of cellular response to oxidative stress. Free Radic. Res. 31, 319-24 (1999).

7. Igarashi, K. et al. Regulation of transcription by dimerization of erythroid factor NF-E2 p45 with small Maf proteins. Nature 367, 568-572 (1994)

8. Kobayashi, M. et al. Identification of the interactive interface and phylogenic conservation of the Nrf2-Keap1 system. Genes Cells 7 , 807-20 (2002).

9. Kobayashi, M. \& Yamamoto, M. Molecular mechanisms activating the Nrf2-Keap1 pathway of antioxidant gene regulation. Antioxid. Redox Signal. 7, 385-94 (2005).

10. Fuse, Y. \& Kobayashi, M. Conservation of the Keap1-Nrf2 System: An Evolutionary Journey through Stressful Space and Time. Molecules 22, 1-22 (2017).

11. Martin, M. T. et al. Impact of environmental chemicals on key transcription regulators and correlation to toxicity end points within EPA's toxcast program. Chem. Res. Toxicol. 23, 578-590 (2010).

12. Halder, M., Kienzler, A., Whelan, M. \& Worth, A. EURL ECVAM Strategy to replace, reduce and refine the use of fish in aquatic toxicity and bioaccumulation testing, https://doi.org/10.2788/084219 (2014).

13. Worth, A. et al. Alternative methods for regulatory toxicology - a state-of-the-art review. Science and Policy Report by the Joint Research Centre, https://doi.org/10.2788/11111 (2014).

14. Ankley, G. T. et al. Adverse outcome pathways: A conceptual framework to support ecotoxicology research and risk assessment. Environ. Toxicol. Chem. 29, 730-741 (2010).

15. Garcia, G. R., Noyes, P. D. \& Tanguay, R. L. Advancements in zebrafish applications for 21st century toxicology. Pharmacol. Ther. 161, 11-21 (2016).

16. Zacharewski, T. In vitro bioassays for assessing estrogenic substances. Environ. Sci. Technol. 31, 613-623 (1997).

17. Ankley, G. et al. Overview of a workshop on screening methods for detecting potential (anti-) estrogenic/androgenic chemicals in wildlife. Environ. Toxicol. Chem. 17, 68-87 (1998).

18. Mueller, S. O. Xenoestrogens: mechanisms of action and detection methods. Anal. Bioanal. Chem. 378, 582-587 (2004).

19. Leusch, F. D. L. \& Snyder, S. A. Bioanalytical tools: half a century of application for potable reuse. Environ. Sci. Water Res. Technol. 1, 606-621 (2015)

20. Romøren, K., Thu, B. J., Bols, N. C. \& Evensen, Ø. Transfection efficiency and cytotoxicity of cationic liposomes in salmonid cell lines of hepatocyte and macrophage origin. Biochim. Biophys. Acta-Biomembr. 1663, 127-134 (2004).

21. Horibe, T. et al. Transfection efficiency of normal and cancer cell lines and monitoring of promoter activity by single-cell bioluminescence imaging. Luminescence 29, 96-100 (2014).

22. Slaninova, A., Smutna, M., Modra, H. \& Svobodova, Z. A review: oxidative stress in fish induced by pesticides. Neuro Endocrinol. Lett 30(Suppl 1), 2-12 (2009).

23. Vallone, D., Santoriello, C., Gondi, S. B. \& Foulkes, N. S. Basic protocols for zebrafish cell lines: maintenance and transfection. Methods Mol. Biol. 362, 429-41 (2007).

24. Culp, P. A. Random DNA Integrations as an Approach to Insertional Mutagenesis in the Zebrafish. Gene (Massachusetts Institute of Technology, 1994).

25. Driever, W. \& Rangini, Z. Characterization of a cell line derived from zebrafish (Brachydanio rerio) embryos. In Vitro Cell. Dev. Biol. Anim. 29A, 749-54 (1993).

26. Ghosh, C., Zhou, Y. L. \& Collodi, P. Derivation and characterization of a zebrafish liver cell line. Cell Biol. Toxicol. 10, 167-176 (1994).

27. Eide, M., Rusten, M., Male, R., Jensen, K. H. M. \& Goksøyr, A. A characterization of the ZFL cell line and primary hepatocytes as in vitro liver cell models for the zebrafish (Danio rerio). Aquat. Toxicol. 147, 7-17 (2014).

28. Lazic, S. E. The problem of pseudoreplication in neuroscientific studies: is it affecting your analysis? BMC Neurosci. 11, 5 (2010).

29. Sharma, A. K., Taneja, G., Khanna, D. \& Rajput, S. K. Reactive oxygen species: friend or foe? RSC Adv. 5, 57267-57276 (2015)

30. Kroon, F., Streten, C. \& Harries, S. A protocol for identifying suitable biomarkers to assess fish health: A systematic review. PLoS ONE 12, (2017)

31. Rousseau, M. E. et al. Regulation of Ahr signaling by Nrf2 during development: Effects of Nrf2a deficiency on PCB126 embryotoxicity in zebrafish (Danio rerio). Aquat. Toxicol. 167, 157-171 (2015).

32. Hahn, M. E., Timme-Laragy, A. R., Karchner, S. I. \& Stegeman, J. J. Nrf2 and Nrf2-related proteins in development and developmental toxicity: Insights from studies in zebrafish (Danio rerio). Free Radic. Biol. Med. 88, 275-289 (2015).

33. Liu, H. et al. A rapid in vivo zebrafish model to elucidate oxidative stress-mediated PCB126-induced apoptosis and developmental toxicity. Free Radic. Biol. Med. 84, 91-102 (2015).

34. Kusik, B. W., Carvan, M. J. \& Udvadia, A. J. Detection of mercury in aquatic environments using EPRE reporter zebrafish. Mar. Biotechnol. 10, 750-757 (2008).

35. Kobayashi, M. et al. The antioxidant defense system Keap1-Nrf2 comprises a multiple sensing mechanism for responding to a wide range of chemical compounds. Mol. Cell. Biol. 29, 493-502 (2009).

36. Tsujita, T. et al. Nitro-fatty acids and cyclopentenone prostaglandins share strategies to activate the Keap1-Nrf2 system: a study using green fluorescent protein transgenic zebrafish. Genes Cells 16, 46-57 (2011).

37. Lundqvist, J., Hellman, B. \& Oskarsson, A. Fungicide prochloraz induces oxidative stress and DNA damage in vitro. Food Chem. Toxicol. 91, 36-41 (2016).

38. Lundqvist, J., Pekar, H. \& Oskarsson, A. Microcystins activate nuclear factor erythroid 2-related factor 2 (Nrf2) in human liver cells in vitro - Implications for an oxidative stress induction by microcystins. Toxicon 126, 47-50 (2017).

39. Neale, P. A. et al. Development of a bioanalytical test battery for water quality monitoring: Fingerprinting identified micropollutants and their contribution to effects in surface water. Water Res. 123, 734-750 (2017).

40. Stalter, D., O'Malley, E., Von Gunten, U. \& Escher, B. I. Fingerprinting the reactive toxicity pathways of 50 drinking water disinfection by-products. Water Res. 91, 19-30 (2016).

41. Emter, R., Ellis, G. \& Natsch, A. Performance of a novel keratinocyte-based reporter cell line to screen skin sensitizers in vitro. Toxicol. Appl. Pharmacol. 245, 281-290 (2010).

42. Elia, A. C., Waller, W. T. \& Norton, S. J. Biochemical responses of bluegill sunfish (Lepomis macrochirus, Rafinesque) to atrazine induced oxidative stress. Bull. Environ. Contam. Toxicol. 68, 809-16 (2002).

43. Timme-Laragy, A. R. et al. Glutathione redox dynamics and expression of glutathione-related genes in the developing embryo. Free Radic. Biol. Med. 65, 89-101 (2013).

44. Sant, K. E. et al. The role of Nrf1 and Nrf2 in the regulation of glutathione and redox dynamics in the developing zebrafish embryo. Redox Biol. 13, 207-218 (2017).

45. Neale, P. A. et al. Linking in Vitro Effects and Detected Organic Micropollutants in Surface Water Using Mixture-Toxicity Modeling. Environ. Sci. Technol. 49, 14614-14624 (2015).

46. Escher, B. I. et al. Water quality assessment using the AREc32 reporter gene assay indicative of the oxidative stress response pathway. J. Environ. Monit. 14, 2877 (2012).

47. König, M. et al. Impact of untreated wastewater on a major European river evaluated with a combination of in vitro bioassays and chemical analysis. Environ. Pollut. 220, 1220-1230 (2017).

48. Carvan, M. J. 3rd, Solis, W. A., Gedamu, L. \& Nebert, D. W. Activation of transcription factors in zebrafish cell cultures by environmental pollutants. Arch Biochem Biophys 376, 320-327 (2000). 
49. Carvan, M. J. et al. Oxidative stress in zebrafish cells: Potential utility of transgenic zebrafish as a deployable sentinel for site hazard ranking. Sci. Total Environ. 274, 183-196 (2001).

50. Fourquet, S., Guerois, R., Biard, D. \& Toledano, M. B. Activation of NRF2 by nitrosative agents and $\mathrm{H}_{2} \mathrm{O}_{2}$ involves KEAP1 disulfide formation. J. Biol. Chem. 285, 8463-71 (2010).

51. Li, L. et al. Molecular evolution of Keap1. Two Keap1 molecules with distinctive intervening region structures are conserved among fish. J. Biol. Chem. 283, 3248-55 (2008).

52. Saito, R. et al. Characterizations of Three Major Cysteine Sensors of Keap1 in Stress Response. Mol. Cell. Biol. 36, 271-84 (2015).

53. Costin, D., Staicu, A., Huculeci, R., Stoian, G. \& Costache, M. Renal Effects of Deltamethrin Induced Intoxication in Carassius auratus gibelio (Pisces cyprinidae) **. 23, 399-404 (2007).

54. Dinu, D. et al. Modulatory effects of deltamethrin on antioxidant defense mechanisms and lipid peroxidation in carassius auratus gibelio liver and intestine. Arch. Environ. Contam. Toxicol. 58, 757-764 (2010).

55. Atif, F. et al. Modulatory effect of cadmium exposure on deltamethrin-induced oxidative stress in Channa punctata Bloch. Arch. Environ. Contam. Toxicol. 49, 371-377 (2005).

56. Sayeed, I. et al. Oxidative stress biomarkers of exposure to deltamethrin in freshwater fish, Channa punctatus Bloch. Ecotoxicol. Environ. Saf. 56, 295-301 (2003).

57. Ensibi, C. et al. Effects of deltamethrin on biometric parameters and liver biomarkers in common carp (Cyprinus carpio L.). Environ. Toxicol. Pharmacol. 36, 384-391 (2013).

58. Pimpão, C. T., Zampronio, A. R. \& Silva de Assis, H. C. Effects of deltamethrin on hematological parameters and enzymatic activity in Ancistrus multispinis (Pisces, Teleostei). Pestic. Biochem. Physiol. 88, 122-127 (2007).

59. Guiloski, I. C., Rossi, S. C., da Silva, C. A. \& de Assis, H. C. S. Insecticides biomarker responses on a freshwater fish Corydoras paleatus (Pisces: Callichthyidae). J. Environ. Sci. Health. B. 48, 272-7 (2013).

60. Anand, S. S. et al. Characterization of deltamethrin metabolism by rat plasma and liver microsomes. Toxicol. Appl. Pharmacol. 212, 156-166 (2006).

61. Hosokawa, M. et al. Genomic structure and transcriptional regulation of the rat, mouse, and human carboxylesterase genes. Drug Metab. Rev. 39, 1-15 (2007).

62. Jeong, Y. et al. Differential Effects of CBZ-Induced Catalysis and Cytochrome Gene Expression in Three Dimensional Zebrafish Liver CellCulture. J. Environ. Anal. Toxicol. 6, (2016).

63. Miranda, C., Collodi, P., Zhao, X., Barnes, D. W. \& Buhler, D. R. Regulation of Cytochrome P450 Expression in a Novel Liver Cell Line from Zebrafish (Brachydanio rerio). Arch. Biochem. Biophys. 305, 320-327 (1993).

64. Oruç, E. Ö. \& Usta, D. Evaluation of oxidative stress responses and neurotoxicity potential of diazinon in different tissues of Cyprinus carpio. Environ. Toxicol. Pharmacol. 23, 48-55 (2007).

65. Oruc, E. Effects of diazinon on antioxidant defense system and lipid peroxidation in the liver of Cyprinus carpio (L.). Environ. Toxicol. 26, 571-578 (2011).

66. Dutta, H. M., Richmonds, C. R. \& Zeno, T. Effects of diazinon on the gills of bluegill sunfish Lepomis macrochirus. J. Environ. Pathol. Toxicol. Oncol. 12, 219-227 (1993).

67. Li, W., Yin, D., Zhou, Y., Hu, S. \& Wang, L. 3,4-dichloroaniline-induced oxidative stress in liver of crucian carp (Carassius auratus). Ecotoxicol. Environ. Saf. 56, 251-5 (2003).

68. Rossi, S. C. et al. Sublethal effects of waterborne herbicides in tropical freshwater fish. Bull. Environ. Contam. Toxicol. 87, 603-607 (2011).

69. Kienzler, A., Tronchère, X., Devaux, A. \& Bony, S. Assessment of RTG-W1, RTL-W1, and PLHC-1 fish cell lines for genotoxicity testing of environmental pollutants by means of a Fpg-modified comet assay. Toxicol. In Vitro 26, 500-10 (2012).

70. Fao. Fao Specifications and Evaluations for Plant Protection Products: Metazachlor. Food and Agriculture Organization of the United Nations (1999)

71. Brancato, A. et al. Peer review of the pesticide risk assessment for the active substance metazachlor in light of confirmatory data submitted. EFSA J. 15 (2017).

\section{Acknowledgements}

This work was financially supported by the Swedish Research Council (grant no. 2015-03404), the Research Council Formas (grant no. 2014-1435), the Royal Swedish Academy of Agriculture and Forestry (grant no. H14-0162-CHF) and the Swedish Fund for Research Without Animal Experiments (grant no. N2016-0007). The authors are grateful to Professor Nicholas Foulkes, Institute for Toxicology and Genomics, KIT Karlsruhe, Germany and Associate Professor Joachim Sturve, Department of Biological and Environmental Sciences, University of Gothenburg, Sweden, for generous gifts of research materials.

\section{Author Contributions}

S.L.-M. performed the practical work, data handling, and wrote the manuscript. A.O. and J.L. supervised the project and revised the manuscript.

\section{Additional Information}

Supplementary information accompanies this paper at https://doi.org/10.1038/s41598-018-30880-1.

Competing Interests: The authors declare no competing interests.

Publisher's note: Springer Nature remains neutral with regard to jurisdictional claims in published maps and institutional affiliations.

(c) (i) Open Access This article is licensed under a Creative Commons Attribution 4.0 International

License, which permits use, sharing, adaptation, distribution and reproduction in any medium or format, as long as you give appropriate credit to the original author(s) and the source, provide a link to the Creative Commons license, and indicate if changes were made. The images or other third party material in this article are included in the article's Creative Commons license, unless indicated otherwise in a credit line to the material. If material is not included in the article's Creative Commons license and your intended use is not permitted by statutory regulation or exceeds the permitted use, you will need to obtain permission directly from the copyright holder. To view a copy of this license, visit http://creativecommons.org/licenses/by/4.0/.

(c) The Author(s) 2018 